\title{
Bio2010: Read It!
}

\section{Review of: Bio2010: Transforming Undergraduate Education for Future Research Biologists, by the National Research Council of the National Academies, 2003; 191 pp; National Academies of Science (Washington, DC); ISBN: 0-309-08535-7; www.nap.edu}

\section{Reviewed by Douglas Fambrough, Johns Hopkins University}

Submitted March 31, 2003; Accepted April 4, 2003

In the few minutes it will take you to read these comments on the National Research Council's report Bio2010: Transforming Undergraduate Education for Future Research Biologists, you could go online and order a copy from http://www.nap.edu/catalog/10497.html. Please do that now.

Kerry Brenner provides a very brief overview of Bio2010 in this Features section of $C B E$, and Joan Steitz, a member of the authoring committee, discusses the genesis of the report. My task here is to point out other important aspects of the report and offer some comments inspired by it.

As a soft-bound volume, the main text of Bio2010 runs about 190 small, easy-to-read pages that are formatted expertly to support the flow of topics, examples, and recommendations. The Bio2010 Committee took pains to obtain input from blueribbon groups of chemists, physicists, engineers, and mathematicians and computer scientists. A draft report was further reviewed by another group of first-rate scientists. This care to do the job extremely well is evident in the final report. It is concisely written, judiciously documented, information-rich, interesting, thoughtful, and helpful.

Although the charge to the committee was to address the undergraduate educational needs of future biomedical research scientists, the report recognizes the relatively tiny size of this group of students compared with the huge number of biology majors (roughly 85,000 graduate each year) and makes a convincing case that many of the suggestions and recommendations are meant to benefit biology majors in general. It is clear that the committee also kept in mind the challenges of $\mathrm{K}-12$ education and the probability that those going into biomedical research would continue through a graduate or professional school program. The report argues that for undergraduate training in biology, only a limited amount of specialization within the biology major seems justified.

Four examples of curricula for the biology major are provided. As the report points out, some of these curricula do not seem very different from those typically in place now. To a large extent the course names can remain, but course contents need revision. All of these curricula are designed

DOI: $10.1187 /$ cbe.03-03-0015

Corresponding reviewer. E-mail address: fambro@jhu.edu.

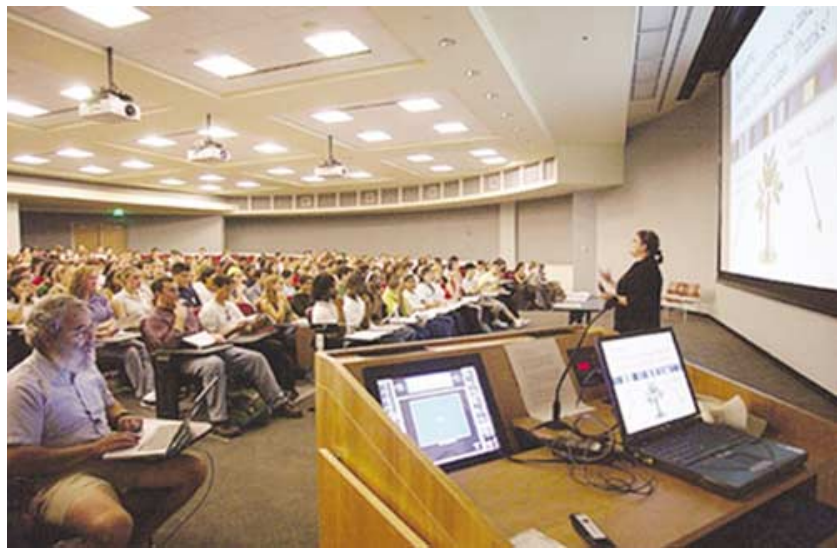

Professor Becky Pearlman lecturing to a general biology class at Johns Hopkins University. (Reprinted with permission from Arts \& Sciences Update, Winter/Spring issue, p. 3. Copyright Johns Hopkins University, 2003.)

to provide a strong foundation in those aspects of chemistry, physics, mathematics and computer science that are relevant to biological research. Since adding anything to the present curriculum means removing something else, the report discusses some of the possible trade-offs involved, for example, in restructuring chemistry and mathematics courses to serve the needs of biology majors. All four of the suggested curricula contain a Fall-semester sophomore course in molecular biology followed by a Spring-semester course in cell and developmental biology.

The report stresses that biology majors should understand the central concepts of chemistry, physics, engineering, and biology and the reality that biological research will increasingly involve a fusion of all these sciences plus the use of mathematical and other tools for modeling, visualization, risk assessment, and so forth. Boldly, the report actually provides lists of what these major concepts and tools are. The lists can serve as a concise guide for those involved in curriculum reform.

A recurring theme in the report is the importance that student-mentor interactions play in development of biomedical research scientists. Richard Feynman is quoted early in the report: ". . . The best teaching can only be done when there is a direct individual relationship between a student and a good 
teacher.... It's impossible to learn very much by sitting in a lecture..." While Bio2010 strongly urges upgrading course content, the need for students to participate actively in research is presented as an essential component of undergraduate biology education. Bio2010 suggests project-based laboratory exercises, seminar courses with project components, independent research for credit, and interdisciplinary courses in modeling. For help in developing or upgrading these activities, a variety of sources is identified. The report also stresses the need for university administrators to support faculty in these mentoring roles, for example, by giving faculty credit for instructional time spent in these activities.

I have always thought of curriculum reform as being both an extremely important, ongoing part of academic science and a rat hole down which you are free to pour as much energy as you like. Bio2010 acknowledges and even enumerates the rather daunting barriers to improving undergraduate education in biology. Prominent among these barriers are the typical lack of rewards for innovative teaching, the lack of financial support from institutions, and the restrictions upon course reform due to medical school admission requirements. However, the report offers itself as one weapon in the fight for better undergraduate education. Its recommenda- tions carry the prestige and weight of the National Academy of Sciences and the eminent scientists who wrote the report. In addition, the report identifies many potential sources of help, both intellectual and financial. It also provides many short examples of successful innovations in teaching biology, and it describes the roles various professional societies are playing, such as fostering the development and dissemination of teaching "modules" and providing opportunities for undergraduates to participate in workshops and summer courses.

If Bio2010 has any shortcomings, one that struck me was that it includes the tacit assumption that the students are passive in the curriculum reform process. How interesting it would be if undergraduates had more understanding of what education they should expect their school to provide! Suppose they all read the Bio2010 and began to ask, How does my curriculum compare with the NRC report's vision?

The foreword to Bio2010 mentions that the National Academies have produced dozens of reports on education in recent years, several of which might be useful resources for college faculty. To my knowledge, none of these has become popular reading in the trenches. Let us hope that Bio2010 is the exception that catalyzes a significant improvement in our training of the next generation of scientists. 